06

\title{
Эволюция массотранспортных свойств структурно-модифицированных электродов для топливных элементов и электролизеров воды
}

\author{
(C) Н.В. Глебова, А.О. Краснова, А.А. Нечитайлов \\ Физико-технический институт им. А.Ф. Иофрфе РАН, \\ 194021 Санкт-Петербург, Россия \\ e-mail: aan.shuv@mail.ioffe.ru
}

Поступило в Редакцию 13 апреля 2021 г. В окончательной редакции 21 мая 2021 г. Принято к публикации 23 мая 2021 г.

\begin{abstract}
Методом дискового электрода (стационарного и вращающегося) исследованы закономерности изменения массотранспортных свойств композитных электродов, содержащих наночастицы платины на углеродной саже, добавку углеродного материала с различной формой структурных элементов (трехмерные и псевдоодномерные углеродные нанотрубки с различным отношением длины к диаметру), протонпроводящий полимер Nafion. Исследован транспорт молекулярного кислорода внутри пористого электрода к поверхности платины. Предложены механизмы изменения массотранспортных свойств структурно-модифицированных электродов в процессе электрохимического воздействия.
\end{abstract}

Ключевые слова: иономер, платина, протонпроводящий полимер Nafion, УНТ.

DOI: 10.21883/JTF.2021.11.51530.107-21

\section{Введение}

Вопросам стабильности и механизмам деградации электрохимических электродов со смешанной проводимостью, используемых в низкотемпературных электрохимических устройствах (топливные элементы, электролизеры воды) уделяется много внимания, о чем свидетельствует обширный и пополняющийся перечень научных публикаций [1-6]. Себестоимость подобных электрохимических устройств на сегодняшний день во многом ограничивает их широкое использование, несмотря на множество преимуществ прямой конверсии энергии, происходящей в них. Одна из причин высокой себестоимости устройств - недостаточно длительный срок службы.

Суть публикуемых работ сводится к отражению нескольких основных аспектов проблемы стабильности и долговечности электрохимических систем: стабильности компонентов $[1,6]$, методов ускоренных методик исследования $[4,5]$, технологических приемов увеличения долговременности функционирования [2,3], исследования механизмов деградации [3,5] и некоторых других. В обзоре [5] обсуждаются вопросы современного состояния знаний о стабильности различных топливных элементов с протонпроводящей мембраной, о механизмах их деградации, методиках ускоренного исследования. Отметим, что в современных работах неким пробелом являются исследования такой важной с практической точки зрения характеристики, как массотранспортные потери внутри пористого электрода в свете их изменения при длительном функционировании. Между тем с внедрением в технологию современных электродов различных функциональных добавок, модифицирующих структуру [1,7], возрастает актуальность исследования стабильности таких электродов. Учитывая тот факт, что введение структурирующих добавок направлено зачастую на интенсификацию массопереноса внутри электрода и связано с изменением структуры протонпроводящего полимера, актуальность исследований массового транспорта в таких электродах в процессе их длительного функционирования возрастает. Мы считаем, что сказанное вполне мотивирует проведение исследований эволюции массотранспортных свойств структурномодифицированных электродов при длительном электрохимическом воздействии, в чем и заключается цель настоящей работы.

\section{1. Эксперимент}

Для получения экспериментальных данных использован дисковый вращающийся электрод (ДВЭ) [8-10]. ДВЭ представляет собой диск из проводящего материала (в нашем случае из стеклоуглерода), запрессованный в изолирующую фторопластовую оболочку. Проводящий диск электрически связан с измерительной цепью экспериментальной установки, электрод может приводиться во вращение с заданной частотой оборотов.

В качестве экспериментальных образцов использовали нанесенные на стеклоуглеродную поверхность дискового электрода материалы различного компонентного состава, содержащие добавки „коротких“ и „длинных“ углеродных нанотрубок (УНТ) и материалы без добавок. Дисковый электрод с нанесенным материалом помещали в стандартную измерительную установку, 


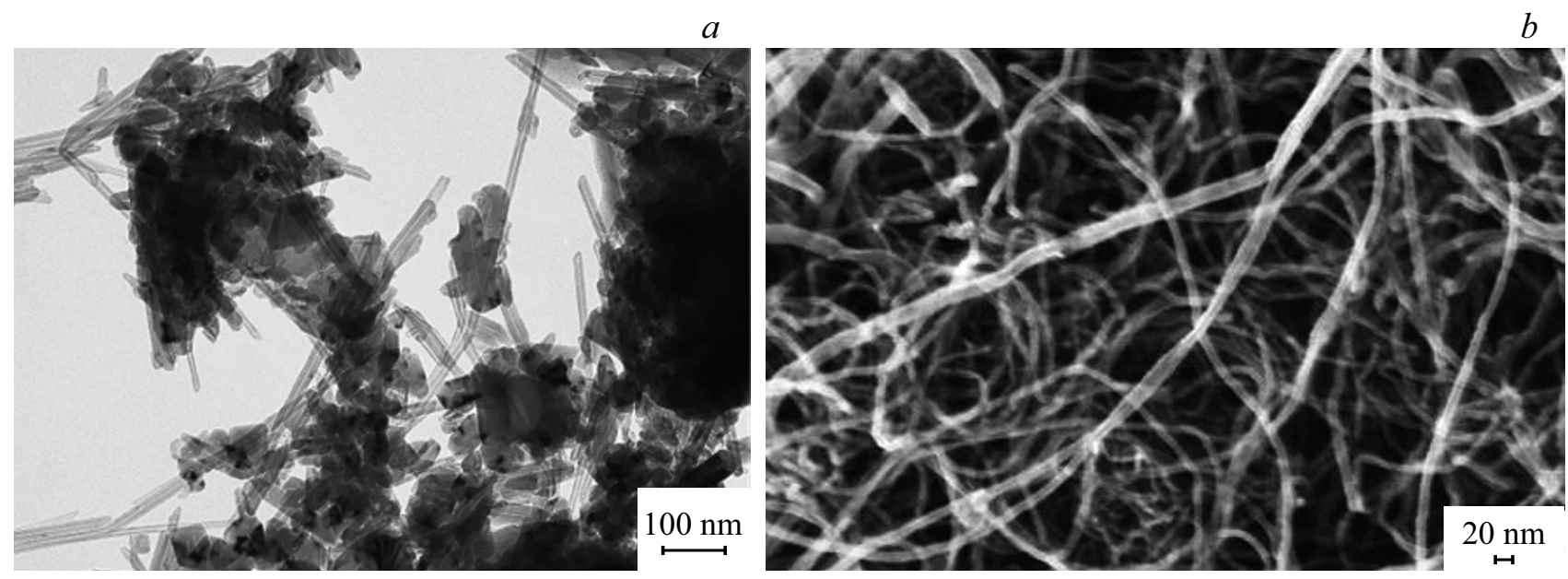

Рис. 1. Микрофотографии углеродных наноструктурированных материалов, использованных в качестве добавок: $a-$ ПЭМ изображение углеродного наноматериала Плазмас; $b-$ СЭМ изображение многостенных углеродных нанотрубок Таунит МД.

состоящую из устройства вращения, трехэлектродной электрохимической ячейки, потенциостата и управляющего компьютера. В качестве раствора электролита использовали $0.5 \mathrm{M}$ раствор серной кислоты. Электрохимическое воздействие на исследуемые электроды осуществляли путем многократного циклического изменения их электродного потенциала. При этом через определенное количество циклов проводили исследования комплекса характеристик электрода, таких, как площадь электрохимически активной поверхности платины, величина суммарной электрохимически активной поверхности, величина предельного тока восстановления молекулярного растворенного кислорода. Таким образом получали набор экспериментальных данных, позволяющих судить об изменении свойств электрода в процессе деградации.

\section{1. Использованные материалы}

Использовали композитные электродные материалы, содержащие платинированную углеродную сажу, протонпроводящий полимер Nafion, модифицирующие структуру добавки - многостенные углеродные нанотрубки.

\subsection{1. Платинированная углеродная сажа (Pt/C)}

Использовали коммерческий продукт под маркой E-TEK, содержащий 20 и 40\% платины на углеродной саже Vulcan XC-72 [11]. Удельная площадь поверхности составляет 200 [12]-250 $\mathrm{m}^{2} / \mathrm{g}$ [13-16].

\subsection{2. Протонпроводящий полимер Nafion}

Для введения иономера в электродный материал использовали коммерческий продукт IonPowerInc.
DUPONT DE2020 - водно-пропанольный раствор Nafion концентрации $20 \%$.

\subsection{3. Добавки наноструктурированных углеродных материалов}

Использовали „короткие“ и ,длинные“ многостенные углеродные нанотрубки. На рис. 1 представлены микрофотографии использованных материалов-добавок.

\subsection{4. „Короткие“ УНТ Плазмас}

Использованные в работе УНТ охарактеризованы методами электронной микроскопии, EDX и адсорбционноструктурного анализа по низкотемпературной адсорбции азота. Удельная площадь поверхности УНТ, измеренная по низкотемпературной адсорбции азота, составляла $13 \mathrm{~m}^{2} / \mathrm{g}$. Диаметр трубок колеблется в интервале $12-33 \mathrm{~nm}$. Однако преимущественное большинство имеет диаметр 12-14 nm. Длина 200-300 nm. С целью очистки от металлических примесей, УНТ обрабатывали раствором азотной кислоты $(1: 1)$ при температуре $\sim 100^{\circ} \mathrm{C}$ в течение 5 min с последующей многократной промывкой водой и сушкой. Такая обработка приводила к снижению примерно на порядок содержания примесей металлов (табл. 1).

Таблица 1. Элементный состав УНТ Плазмас (\%): исходных и после кислотной обработки

\begin{tabular}{c|c|c}
\hline Элемент & Исходные & После обработки \\
\hline $\mathrm{C}$ & 95.1 & 98.9 \\
$\mathrm{O}$ & 1.36 & 0.45 \\
$\mathrm{Al}$ & 2.63 & 0.34 \\
$\mathrm{Fe}$ & 0.94 & - \\
$\mathrm{S}$ & - & 0.29 \\
$\mathrm{Cумма}$ & 100.03 & 99.98
\end{tabular}


Таблица 2. Структурные характеристики (данные производителя [17]) и элементный состав [12] УНТ Таунит МД

\begin{tabular}{l|c}
\hline \multicolumn{1}{c|}{ Параметр } & Значение \\
\hline Внешний диаметр, $\mathrm{nm}$ & $8-30$ \\
Внутренний диаметр, $\mathrm{nm}$ & $5-15$ \\
Длина, $\mu \mathrm{m}$ & $\geq 20$ \\
Насыпная плотность, $\mathrm{g} / \mathrm{cm}^{3}$ & $0.025-0.06$ \\
Удельная поверхность, $\mathrm{m}^{2} / \mathrm{g}$ & $\geq 200$ \\
Содержание $\mathrm{C}, \%$ mass. & 96.1 \\
Содержание O, \% mass. & 3.86
\end{tabular}

\subsection{5. ,Длинные“ УНТ Таунит МД}

Использовали многостенные углеродные нанотрубки Таунит МД (производство ООО „НаноТехЦентр“, Тамбов) [17].

Характерными структурными свойствами этих нановолокон являются большое отношение длины к диаметру, составляющее $670-2500$, и высокая пористость за счет пор больше $100 \mathrm{~nm}[12])$. УНТ были очищены от примесей катализаторов, используемых при их получении посредством кислотной обработки, промывки дистиллированной водой и сушки. В качестве кислоты использовали азотную кислоту, разбавленную водой в объемном отношении $1: 1$. Обработку вели при температуре около $100^{\circ} \mathrm{C}$ в течение $\sim 15 \mathrm{~min}$. Была выбрана азотная кислота, так как она наиболее полно растворяет примеси (установлено опытным путем).

Характеристики используемых УНТ после очистки представлены в табл. 2. Наличие в материале значительного количества кислорода связано с его присоединением в процессе кислотной обработки в окислительной среде.

\section{2. Образцы}

Исходным электродным материалом для образцов служили дисперсии твердых компонентов в водноспиртовой среде соответствующего компонентного состава.

\subsection{1. Приготовление дисперсии}

Технологические операции приготовления дисперсии электродного материала включали две стадии: механическое и ультразвуковое диспергирование смеси точных навесок компонентов в смеси и-пропанол-вода. Объемное соотношение жидких составляющих и-пропанол: вода находилось в диапазоне $(1: 1)-(1: 5)$. Отношение твердой фазы к жидкой (т:ж) в конечной дисперсии при этом находилось в диапазоне $(1: 40)-(1: 80)$. Формирование части электродов проводили способом, предусматривающим предварительное коагулирование Nafion из его раствора в жидкой фазе с последующим введением в структуру электрода $[12,18]$. Для этого коммерческий раствор Nafion в заданной концентрации перед добавлением в дисперсию разбавляли водой в объемном отношении $1: 1$.

Механическое диспергирование выполняли на магнитной мешалке Milaform MM-5M со скоростью вращения якоря $\sim 400$ оборотов в минуту с изолированным в пластиковый кожух якорем до визуально однородной (без видимых комочков) массы $\sim 0.5 \mathrm{~h}$. Последующее ультразвуковое диспергирование проводили в ультразвуковой ванне Branson 3510 в течение $40-100 \mathrm{~h}$ до получения однородной, не расслаивающейся в течение минуты дисперсии.

\subsection{2. Нанесение на дисковый вращающийся электрод}

Образцы для исследования на ДВЭ готовили путем нанесения дисперсии компонентов электродного материала на стеклоуглеродную поверхность ДВЭ.

Перед нанесением дисперсии поверхность электрода полировали пастой ГОИ, промывали дистиллированной водой и изопропанолом. Снимали тестовую циклическую вольтамперограмму для оценки холостых токов.

После нанесения капли дисперсии электрод высушивали под вытяжкой на воздухе при комнатной температуре. После этого часть материала, выходящую за пределы стеклоуглеродной поверхности, стирали.

\subsection{3. Проведение измерений}

Измерения проводили в трехэлектродной электрохимической ячейке в растворе $0.5 \mathrm{M}$ серной кислоты, находящейся в равновесии с воздухом при комнатной температуре $\left(\sim 23^{\circ} \mathrm{C}\right)$. В качестве электрода сравнения использовали хлоридсеребряный электрод, в качестве вспомогательного электрода использовали электрод из спектрально-чистого графита. Вращение электрода осуществляли на установке ВЭД-06, совмещенной с потенциостатом IPC Pro. Экспериментальные данные регистрировали на управляющем персональном компьютере в программе IPC-Pro MF 8.70.

Измерение включало в себя очистку электрода, peгистрацию циклических вольтамперограмм (ЦВА), peгистрацию равновесного потенциала рабочего электрода и регистрацию серии полярограмм, снятых при разных скоростях вращения электрода. Также измеряли электрическое сопротивление цепи и фоновый ток.

Очистку проводили путем циклического изменения электродного потенциала в диапазоне от 0.15 до $0.8 \mathrm{~V}$ со скоростью $50 \mathrm{mV} / \mathrm{s}$. При этом регистрировали ЦВА. Очистку проводили до прекращения изменения ЦВА (обычно около 40 циклов). Равновесный потенциал рабочего электрода регистрировали в течение $60 \mathrm{~min}$. Полярограммы регистрировали при различных скоростях вращения ДВЭ в двух направлениях изменения потенциала: от -0.1 до $0.8 \mathrm{~V}$ и обратно со скоростью $1 \mathrm{mV} / \mathrm{s}$. 
Экспериментальное значение силы тока вычисляли как среднее прямого и обратного хода.

Электрическое сопротивление измерительной цепи $\mathrm{R}$ оценивали методом прерывания тока [19].

Фоновый ток рабочего электрода измеряли в рабочем диапазоне потенциалов при нулевой скорости вращения в потенциостатическом режиме. Стабилизация тока происходила в течение $\leq 1 \mathrm{~min}$.

\section{2. Вычисления}

\section{1. Вычисление электрохимически активной площади поверхности платины}

После очистки регистрировали три цикла ЦВА для измерения электрохимически активной площади поверхности платины. Эту величину измеряли в водородной области ЦВА по десорбции водорода [20]. Для этого путем численного интегрирования вычисляли заряд, пошедший на десорбцию водорода. Интегрировали область под ЦВА-кривой, ограниченную снизу горизонтальной линией, которая соответствует току заряжения двойного электрического слоя (ДЭС). Полученный заряд, пошедший на десорбцию водорода, делили на коэффициент, соответствующий заряду водорода, десорбированному с единицы площади поверхности платины $\left(210 \mu \mathrm{C} / \mathrm{cm}^{2}\right)$ в соответствии с соотношением

$$
S_{\mathrm{Pt}}=\left(\int_{E 1}^{E 2} I d E\right) / 210 .
$$

\section{2. Вычисление электрохимически активной суммарной площади пористого электрода}

Использовали известное положение: поляризационная емкость в 16-20 $\mu \mathrm{F}$ соответствует $\sim 1 \mathrm{~cm}^{2}$ поверхности [21]. В соответствии с этим площадь $S$ вычисляли, исходя из скорости поляризации $v$ и тока заряжения ДЭС I по соотношению

$$
S=\frac{I}{v 20 \cdot 10^{-6}} .
$$

\section{3. Коррекция электродного потенциала}

Для вычисления поправки использовали электрическое сопротивление измерительной цепи $R$. По полученным данным делали поправку (вычисляли $E_{\text {correction }}-$ потенциал с учетом поправки) $E$ для каждого текущего значения тока $I$ для экспериментальных полярограмм по соотношению

$$
E_{\text {correction }}=E+I R \text {. }
$$

\section{4. Вычисление предельных плотностей тока}

По полярограммам, снятым при различных скоростях вращения ДВЭ, находили значения предельного тока для каждой скорости вращения ДВЭ. На основе этих значений строили кинетические кривые в координатах Левича: $1 / I=f\left(1 / \omega^{1 / 2}\right)$. Полученные точки аппроксимировали прямыми. Экстраполировали полученные прямые на ось обратных токов, соответствующую бесконечной скорости вращения ДВЭ, и находили величину внутридиффузионного тока по отсечке.

\section{3. Полученные результаты}

Электрохимическому воздействию подвергали ряд образцов различного состава, при этом наиболее перспективный с точки зрения низкого диффузионного сопротивления материал с Таунит МД подвергли более длительному воздействию.

На рис. 2 приведены кинетические кривые образцов, полученные в процессе длительного электрохимического воздействия (циклического изменения электродного потенциала в диапазоне от -0.15 до $0.8 \mathrm{mV}$ ).

Из рисунков видно, что для образцов без добавок кинетические кривые по мере электрохимического воздействия смещаются в область меньших плотностей тока, т.е. происходит увеличение сопротивления массопереносу. При этом процесс сопровождается уменьшением площади электрохимически активной поверхности платины и равновесного потенциала электрода (рис. 3). Для образца, содержащего УНТ Таунит МД, картина иная, плотность предельного тока по мере электрохимического воздействия несколько увеличивается. Причины разного поведения электродов, как нам представляется, связаны с различным характером изменения компонентного состава. В результате электрохимическое воздействие приводит к изменениям компонентного состава электрода в результате электроокисления углерода, растворения и вымывания платины и Nafion. Соотношение скоростей этих процессов для различных компонентов определяет результирующий эффект. В случае образцов без добавок происходит относительно сильное уменьшение поверхности платины, что приводит к увеличению отношения иономер/платина, и соответственно к увеличению диффузионного сопротивления. В случае электрода с ,длинными“ и „короткими“ УНТ (Таунит МД и Плазмас соответственно (рис. 3)) из-за относительно более медленного уменьшения площади поверхности платины можно сделать вывод о преобладании процесса коллоидизации и электрофоретической миграции Nafion, вследствие чего отношение иономер/платина в процессе эксперимента уменьшается.

Динамику вымывания Nafion из электродов в следствие коллоидизации и электрофоретической миграции фиксировать в данных экспериментах не представлялось возможным, это может послужить мотивацией дальнейших исследований. Обращает на себя внимание то, что наклон прямых (рис. 2) несколько меняется в процессе электрохимического воздействия. Мы объясняем это 

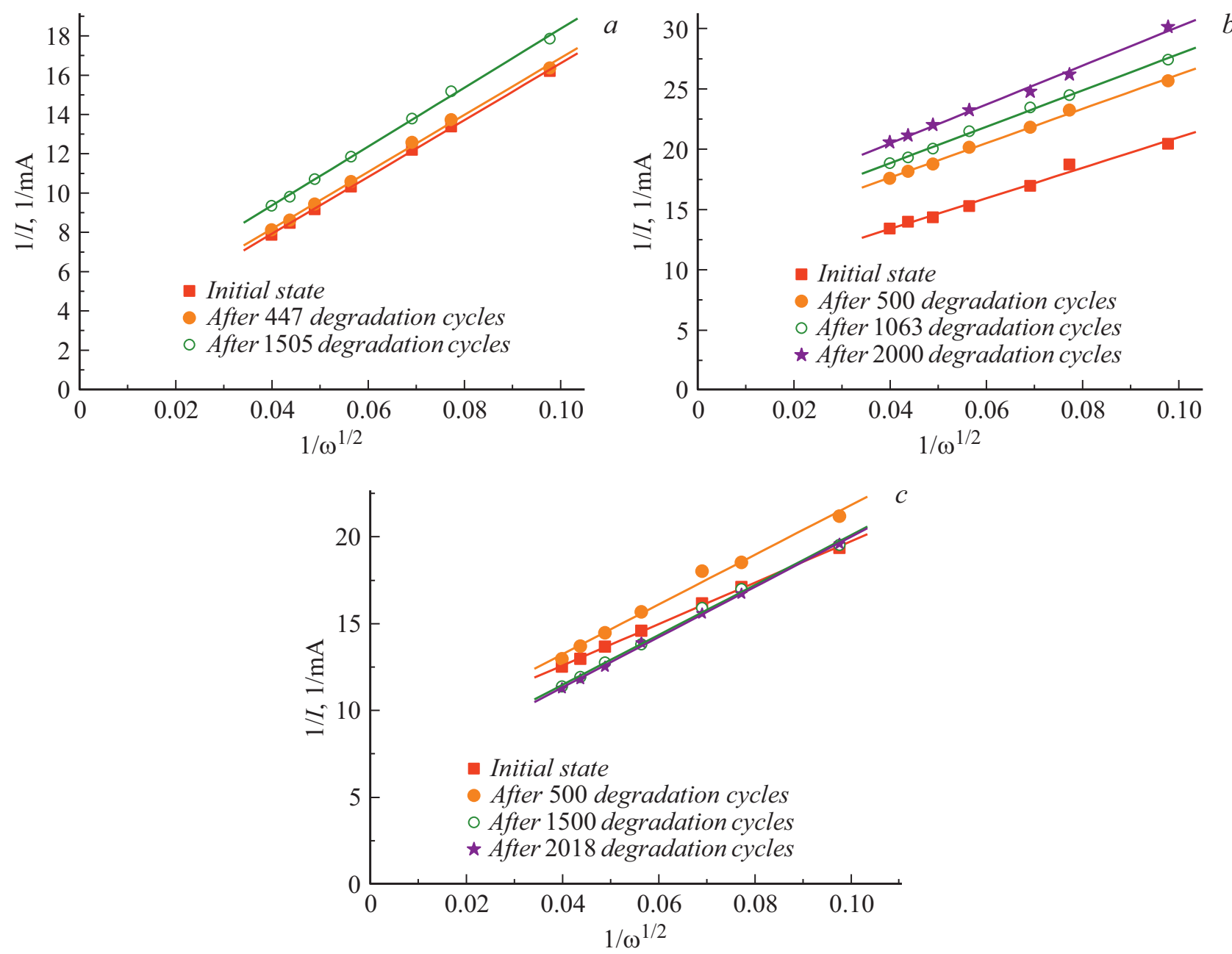

Рис. 2. Кинетические кривые электродов различного состава в процессе длительного электрохимического воздействия: $a-$ $36 \% \mathrm{Pt}+54 \%$ Vulcan $+10 \%$ Nafion; $b-8 \% \mathrm{Pt}+12 \%$ Vulcan $+80 \%$ Nafion; $c-4 \% \mathrm{Pt}+6 \%$ Vulcan $+10 \%$ Таунит МД $+80 \%$ Nafion.

влиянием изменения структуры пористого электрода в процессе деградации.

На рис. 3 представлены циклические вольтамперограммы электродов, а в табл. 3 сведены данные по изменению электродных характеристик образцов в процессе электрохимического воздействия.

Из рис. 3 видно, что в процессе электрохимического воздействия для всех образцов в той или иной мере происходит уменьшение электрохимически активной поверхности платины (уменьшается водородная область, примерный диапазон потенциалов: $-0.15-+0.15 \mathrm{~V})$ и тока заряжения двойного электрического слоя (область потенциалов $0.2-0.6 \mathrm{~V})$. При этом в середине области заряжения ДЭС появляются пики, отвечающие за окислительно-восстановительные процессы, связанные с кислородсодержащими группами на поверхности углеродных материалов [20]. Отметим, что для традиционных электродов на основе платинированной углеродной сажи без добавок процессы деградации более ярко выражены. В случае же электродов, содержащих как „длинные“, так и „короткие“ УНТ (Таунит МД и Плазмас), циклические вольтамперограммы в процессе электрохимического воздействия изменяются гораздо меньше. Кроме того, для электродов на основе платинированной углеродной сажи без добавок деградация происходит быстрее для образца с большим содержанием Nafion $(8 \% \mathrm{Pt}+12 \%$ Vulcan $+80 \%$ Nafion $)$.

Можно предположить, что это связано с коррозионной активностью Nafion и его структурой в электроде (образец без добавок с содержанием Nafion 80\% в противоположность $10 \%$ Nafion). В образце с УНТ Таунит МД также 80\% Nafion, но Nafion структурирован в большой степени в форме отдельных кластеров. Это влечет за собой менее тесный контакт его с платиной и способствует большей стабильности электрода. Образец с „короткими“ УНТ Плазмас содержит небольшое количество Nafion - 8\%. Уменьшение площади электрохимически активной поверхности платины (рис. 4) и площади поверхности углеродного материала в образцах с УНТ Таунит МД и Плазмас происходит существенно медленнее, чем в образце без добавок с содержанием Nafion $10 \%$, который, в свою очередь, стабильнее образца без 

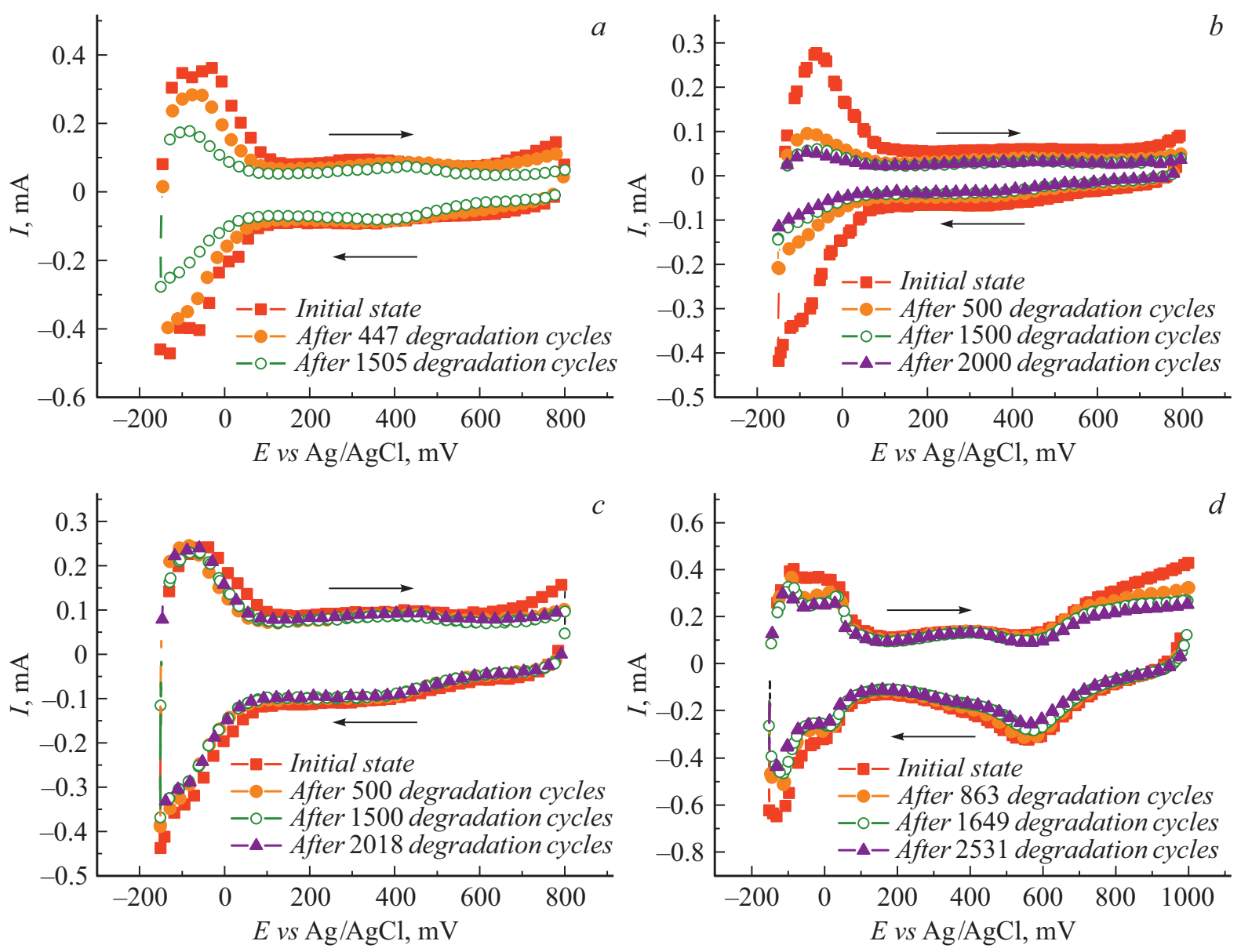

Рис. 3. Циклические вольтамперограммы электродов различного состава в процессе электрохимического воздействия: $a-36 \% \mathrm{Pt}+54 \%$ Vulcan $+10 \%$ Nafion; $b-8 \% \mathrm{Pt}+12 \%$ Vulcan $+80 \%$ Nafion; $c-4 \% \mathrm{Pt}+6 \%$ Vulcan $+10 \%$ Tаунит МД $+80 \%$ Nafion; $d-9 \% \mathrm{Pt}+37 \%$ Vulcan $+46 \%$ Плазмас $+8 \% \mathrm{Nafion}$; стрелками показано направление поляризации; скорость поляризации $50 \mathrm{mV} / \mathrm{s}$.

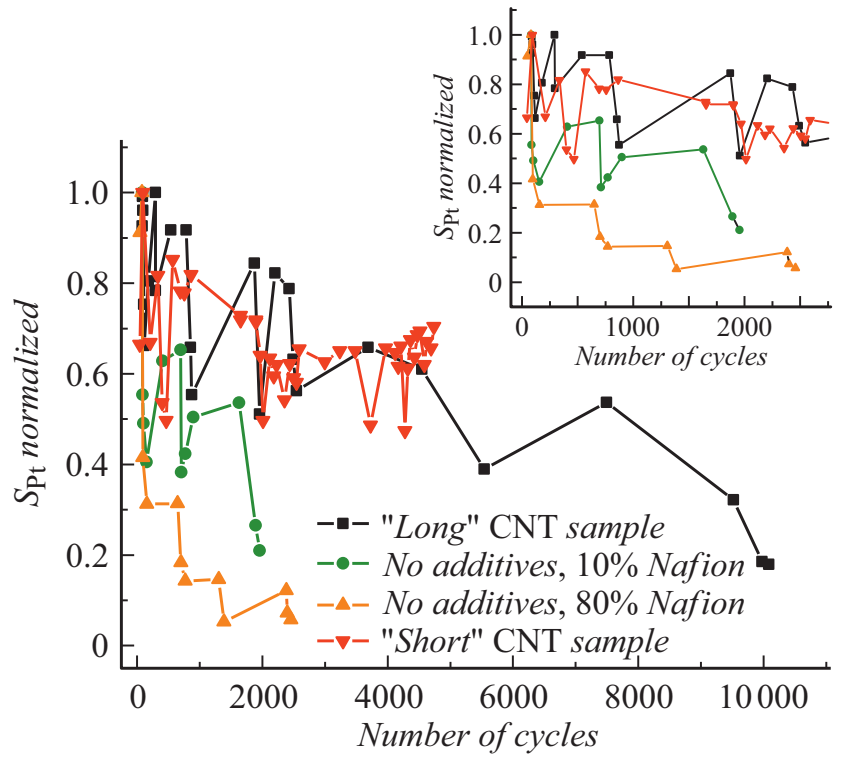

Рис. 4. Динамика нормализованной площади электрохимически активной поверхности платины в процессе электрохимического воздействия; на врезке - начальный участок более детально. добавок с содержанием Nafion $80 \%$. Из рис. 4 видно, что динамика площади электрохимически активной платины для электродов с „длинными“ и „короткими“ УНТ очень близка, однако учитывая, что образец с ,длинными“ УНТ содержит существенно большую долю Nafion, можно сказать, что „длинные“ УНТ способствуют большей стабилизации платины в электроде.

В табл. 3 приведены количественные электродные характеристики различных образцов, измеренные в процессе электрохимического воздействия. В колонке с площадью платины приведены результаты измерения электрохимически активной площади поверхности платины на электроде: два значения через тире, соответствующие площади перед началом и по окончании измерений.

Из табл. 3 видно, что плотность диффузионного тока в процессе электрохимического воздействия для образцов различных систем меняется по-разному. Так, для образцов на основе платинированной углеродной сажи без добавок она уменьшается, в то время как для образцов, содержащих как „короткие“ (Плазмас), так и „длинные“ (Таунит МД) УНТ, - увеличивается. 
Таблица 3. Изменение характеристик электродов в процессе электрохимического воздействия

\begin{tabular}{|c|c|c|c|c|c|c|c|}
\hline $\begin{array}{l}\text { Число } \\
\text { циклов }\end{array}$ & $\begin{array}{c}S_{\mathrm{Pt}} \text { на } \\
\text { ДВЭ, } \mathrm{cm}^{2}\end{array}$ & $\begin{array}{c}I_{D E L}(\text { на } \\
\text { электрод), } \mathrm{mA}\end{array}$ & $\begin{array}{l}E_{e q}, \\
\mathrm{mV}\end{array}$ & $\begin{array}{c}I_{d i f f} \\
\text { (на электрод), mA }\end{array}$ & $\begin{array}{c}\Delta S_{\mathrm{Pt}} \\
\text { на ДВЭ, } \mathrm{cm}^{2}\end{array}$ & $\begin{array}{c}\Delta I_{D E L} \\
\text { (на электрод), } \mathrm{mA}\end{array}$ & $\begin{array}{c}\Delta S_{\text {sum }}, \\
\mathrm{cm}^{2}\end{array}$ \\
\hline \multicolumn{8}{|c|}{$4 \% \mathrm{Pt}+6 \%$ Vulcan $+10 \%$ Таунит МД +,80\%Nafion (,длинные“ УНТ) } \\
\hline $\begin{array}{r}0 \\
500 \\
1500 \\
2018\end{array}$ & $\begin{array}{l}2.51-1.64 \\
2.04-1.24 \\
1.73-1.34 \\
1.85-1.09\end{array}$ & $\begin{array}{l}0.0995 \\
0.0896 \\
0.0880 \\
0.0880\end{array}$ & $\begin{array}{l}660 \\
- \\
652 \\
566\end{array}$ & $\begin{array}{l}0.128 \\
0.133 \\
0.175 \\
0.181\end{array}$ & $\begin{array}{r}- \\
0.47 \\
0.31 \\
-0.12\end{array}$ & $\begin{array}{l}- \\
0.0099 \\
0.0016 \\
0\end{array}$ & $\begin{array}{l}- \\
9.9 \\
1.6 \\
0\end{array}$ \\
\hline \multicolumn{8}{|c|}{ 9\% Pt + 37\%Vulcan + 46\%Плазмас + 8\%Nafion („короткие“ УНТ) } \\
\hline 3987 & $\begin{array}{l}4.90-2.78 \\
3.17-3.43\end{array}$ & $\begin{array}{l}0.124 \\
0.105\end{array}$ & $\begin{array}{l}- \\
-\end{array}$ & $\begin{array}{c}0.542 \\
(R=0.99944) \\
1 / i \approx 0 \\
R=0.99986\end{array}$ & - & 0.019 & $\begin{array}{l}- \\
19\end{array}$ \\
\hline \multicolumn{8}{|c|}{$36 \% \mathrm{Pt}+54 \%$ Vulcan $+10 \%$ Nafion } \\
\hline $\begin{array}{r}0 \\
447 \\
1505\end{array}$ & $\begin{array}{l}2.54-1.66 \\
2.92-1.53 \\
1.41-1.05\end{array}$ & $\begin{array}{l}0.0845 \\
0.0738 \\
0.0633\end{array}$ & $\begin{array}{l}652 \\
622 \\
543\end{array}$ & $\begin{array}{l}0.466 \\
0.420 \\
0.296\end{array}$ & $\begin{array}{l}-\overline{0} \\
1.51\end{array}$ & $\begin{array}{l}- \\
0.0107 \\
0.0105\end{array}$ & $\begin{array}{l}- \\
10.7 \\
10.5\end{array}$ \\
\hline \multicolumn{8}{|c|}{$8 \% \mathrm{Pt}+12 \%$ Vulcan $+80 \%$ Nafion } \\
\hline $\begin{array}{r}0 \\
500 \\
1063 \\
2000\end{array}$ & $\begin{array}{c}2.56-0.8 \\
0.56-0.38 \\
0.47-0.27 \\
0.44-0.19\end{array}$ & $\begin{array}{l}0.0603 \\
0.0391 \\
0.0326 \\
0.0326\end{array}$ & $\begin{array}{l}634 \\
600 \\
526 \\
508\end{array}$ & $\begin{array}{l}0.121 \\
0.0839 \\
0.0783 \\
0.0715\end{array}$ & $\begin{array}{l}- \\
2 \\
0.09 \\
0.03\end{array}$ & $\begin{array}{l}-\overline{-} \\
0.0212 \\
0.0065 \\
0\end{array}$ & $\begin{array}{c}- \\
21.2 \\
6.5 \\
0\end{array}$ \\
\hline
\end{tabular}

Примечание. $S_{\mathrm{Pt}}$ - площадь электрохимически активной поверхности платины; $I_{D E L}-$ ток заряжения ДЭС электрода; $E_{e q}-$ равновесный потенциал электрода; $I_{\text {diff }}$ — диффузионный ток электрода.

Ток заряжения ДЭС, который, как известно, характеризует величину электрохимически активной поверхности электрода, для всех образцов уменьшается. Уменьшается также и площадь электрохимически активной поверхности платины (измеренная отдельно по заряду в водородной области). Уменьшение этих величин наиболее существенно для образца без добавок с содержанием Nafion 80\%. Для него площадь платины уменьшилась более чем на порядок (в 14 раз), тогда как ток заряжения ДЭС уменьшился только в $\sim 1.8$ раза. Учитывая величины уменьшения площади поверхности электрода (табл. 3), можно сказать, что убыль поверхности материала произошла в основном за счет электроокисления углерода.

Образец без добавок с содержанием Nafion 10\% показал аналогичную тенденцию, однако падение как площади платины, так и суммарной площади электрода (тока заряжения ДЭС), существенно меньше.

Образец с ,длинными“ УНТ Таунит МД продемонстрировал самое незначительное уменьшение площади платины и также наименьшее уменьшение площади поверхности электрода за счет углеродных материалов.

Диффузионный ток в процессе электрохимического воздействия для образцов разного состава и структуры ведет себя по-разному (табл. 3, рис. 5). Для образцов без УНТ в процессе „старения“ диффузионный ток падает, для образца с УНТ наблюдается тенденция к его уве- личению до какого-то значения с последующим уменьшением, что отчетливо видно на рис. $5, b$. Отметим, что абсолютные значения диффузионного тока наибольшие для образца без добавок с содержанием Nafion 10\%. Эти особенности мы объясняем влиянием структуры образца. Так, у образцов с содержанием Nafion 80\% (без добавки и с добавкой „длинных“ УНТ) высокое массовое отношение иономера к платине - 10 и 20 соответственно, у образца без добавок с содержанием Nafion 10\% это отношение намного ниже (0.28). Наличие „длинных“ УНТ обеспечивает некоторое пространственное рассогласование платины и Nafion (компоненты находятся на некотором расстоянии) [7], в связи с чем начальная плотность предельного тока в такой структуре даже несколько выше, чем в образце с аналогичным содержанием Nafion без добавки и с меньшим отношением иономер/платина. Деградация для образцов без добавки УНТ сопровождается более резким снижением активной поверхности платины, причем наиболее выражен процесс для образца с большим содержанием Nafion (80\%). Тут сказывается коррозионная активность Nafion. В образце с ,длинными“ УНТ, где платина и Nafion пространственно рассогласованы, наблюдается относительно медленное уменышение поверхности платины в процессе „старения“. Нужно отметить, что в процессе „старения“ изменяется отношение иономер/платина, что сказывается на величине диффузионного тока. Известно, 

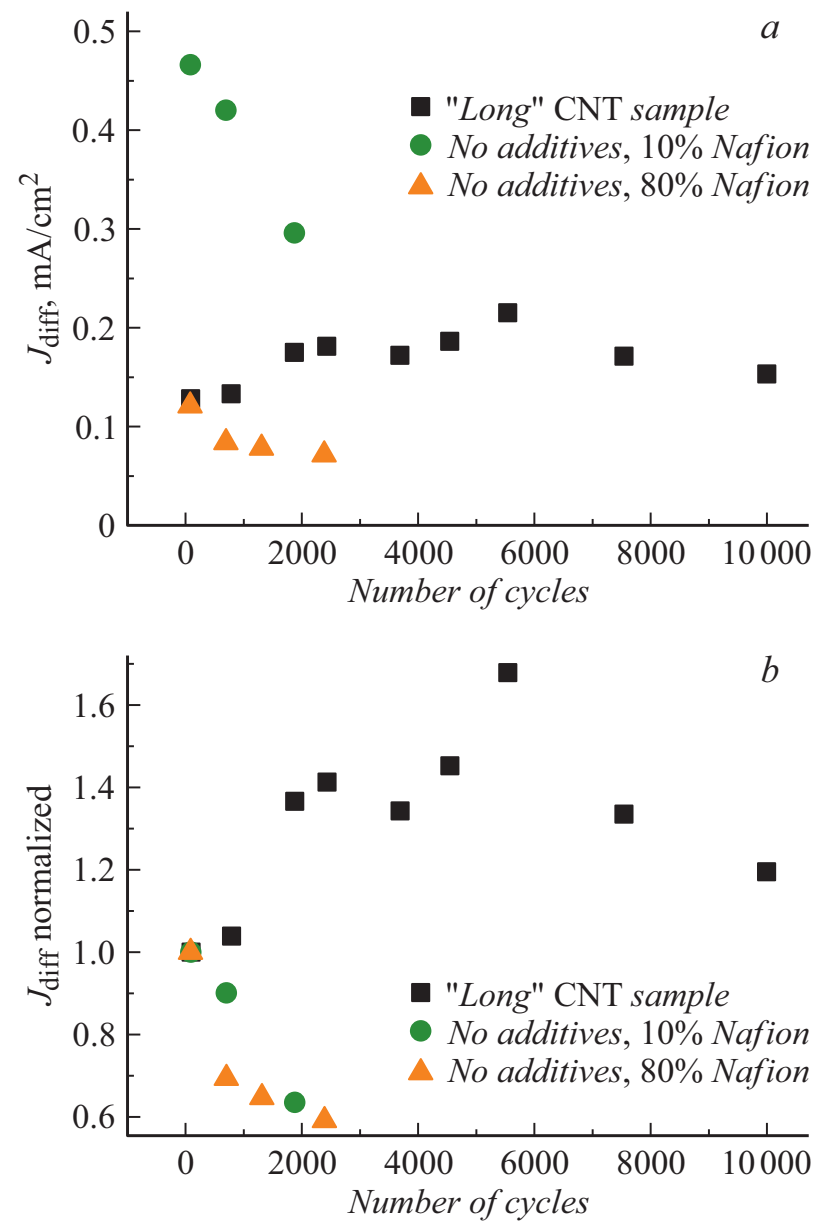

Рис. 5. Динамика диффузионного тока в процессе „старения“ образцов при электрохимическом воздействии (a) и нормализованные на начальное значение плотности диффузионного тока $(b)$.

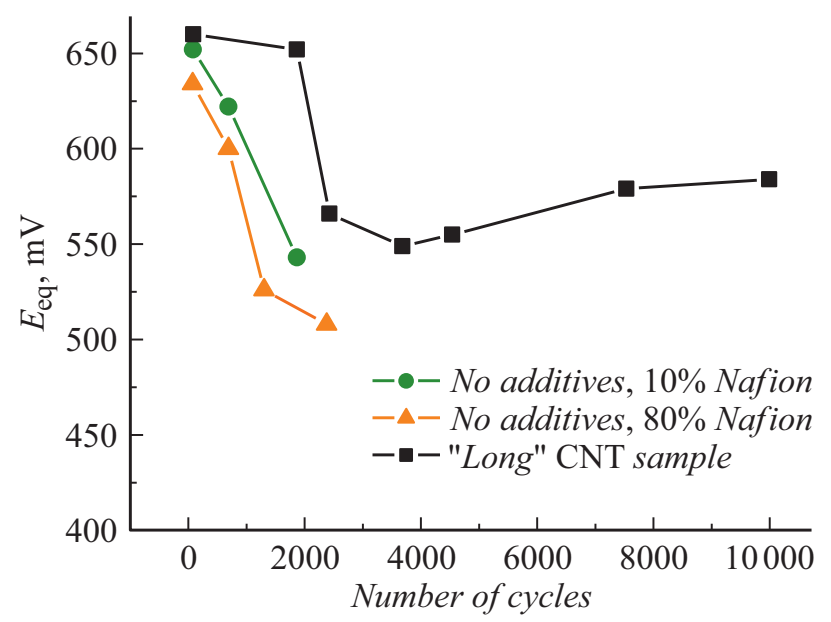

Рис. 6. Изменение равновесного потенциала электродов различного состава в процессе электрохимического воздействия.

что в жидкой среде, в которой проводились измерения на дисковом вращающемся электроде, длина свободного пробега молекул растворенного кислорода существенно меньше, чем в газе, и существенно меньше, чем размер пор исследуемых образцов. В связи с этим с большой вероятностью можно предположить, что диффузионное сопротивление в условиях этого эксперимента обусловлено преодолением слоя Nafion на поверхности платины (или находящегося на пути кислорода). Разный характер изменения диффузионного сопротивления мы связываем с различной скоростью двух процессов: растворения платины и миграции Nafion из структуры электрода, приводящих к различному изменению отношения иономер/платина для различных структур. В случае структуры с пространственно рассогласованными компонентами (в присутствии ,длинных“ УНТ) платина растворяется медленнее. На участке увеличивающейся плотности диффузионного тока преобладает процесс миграции Nafion из структуры электрода.

Равновесный потенциал композитного электрода, который отражает смешанный потенциал, в ходе электрохимического воздействия уменьшается для всех исследованных образцов (табл. 3, рис. 6). Это согласуется с уменьшением поверхности платины в электроде и свидетельствует об изменении соотношения Pt: C в пользу углеродного материала.

\section{Выводы}

1. Деградационные процессы при электрохимическом воздействии сильно зависят от состава и структуры электродов.

2. Nafion является коррозионно-активной средой, при увеличении его содержания увеличивается скорость уменьшения поверхности платины и углеродных компонентов; структурное рассогласование в пространстве компонентов электрода приводит к увеличению их стабильности.

3. Диффузионное сопротивление электрода потоку кислорода к поверхности платины определяется в основном слоем Nafion на ее поверхности и в процессе электрохимического воздействия изменяется по-разному в зависимости от структуры электрода:

- для традиционных материалов - увеличивается за счет увеличения отношения иономер/платина (скорость уменьшения поверхности платины больше скорости миграции Nafion из электродной структуры);

- для материалов, содержащих УНТ, - уменьшается за счет уменьшения отношения иономер/платина (скорость уменьшения поверхности платины меньше скорости миграции Nafion из электродной структуры);

4. Электроды, содержащие УНТ, более устойчивы при электрохимическом воздействии по сравнению с традиционными электродами.

5. „Длинные“ УНТ способствуют большей стабилизации платины в электроде по сравнению с „короткими“. 


\section{Благодарности}

Микроскопические исследования выполнены с использованием оборудования федерального ЦКП „Материаловедение и диагностика в передовых технологиях“, поддержанного Минобрнауки России, уникальный идентификатор проекта RFMEFI62117X0018.

\section{Конфликт интересов}

Авторы заявляют, что у них нет конфликта интересов.

\section{Список литературы}

[1] S.M. Andersen, M. Borghei, P. Lund, Y.-R. Elinad, A. Pasanend, E. Kauppinenb, V. Ruize, P. Kauranend, E.M. Skoua. Solid State Ion., 231, 94 (2013).

DOI: $10.1016 /$ j.ssi.2012.11.020

[2] R.A.M. Esfahani, H.M. Fruehwald, F. Afsahi, E.B. Easton. Appl. Catal. B Environ., 232, 314 (2018).

DOI: 10.1016/j.apcatb.2018.03.080

[3] F. Luo, M. Liu, B. Chi, D. Dang, S. Hou, S. Liao, X. Li, H. Song. J. Appl. Electrochem., 48, 1163 (2018). DOI: $10.1007 / \mathrm{s} 10800-018-1238-7$

[4] L. Vichard, R. Petrone, F. Harel, A. Ravey, P. Venet, D. Hissel. Energy Convers. Manag., 212, 112813 (2020). DOI: $10.1016 /$ j.enconman.2020.112813

[5] J. Zhao, X. Li. Energy Convers. Manag., 199, 112022 (2019). DOI: 10.1016/j.enconman.2019.112022

[6] V. Menshchikov, A. Alekseenko, V. Guterman, A. Nechitailov, N. Glebova, A. Tomasov, O. Spiridonova, S. Belenov, N. Zelenina, O. Safronenko. J. Nanomater., 10 (4), 742 (2020). DOI: $10.3390 /$ nano10040742

[7] А.А. Нечитайлов, Н.В. Глебова, А.О. Краснова. ЖСХ, 60 (9), 1567 (2019). DOI: 10.26902/JSC_id46206

[A.A. Nechitailov, N.V. Glebova, A.O. Krasnova. J. Struct. Chem., 60 (9), 1507 (2019). DOI: $10.1134 / \mathrm{S} 0022476619090166]$

[8] Ю.В. Плесков, В.Ю. Филиновский. Вращающийся дисковый электрод (Наука, М., 1972)

[9] Ю.В. Плесков, В.Ю. Филиновский. Итоги науки и техники, сер. „Электрохимия“, 11, 57 (1976).

[10] Кинетика сложных электрохимических реакций, под ред. В.Е. Казаринова (Наука, М., 1981)

[11] Электронный ресурс. Режим доступа: URL: https://www.fuelcellstore.com/spec-sheets/vulcan-xc72-specsheet.pdf

[12] А.О. Краснова, Н.В. Глебова, А.А. Нечитайлов. ЖПХ, 89 (6), 756 (2016). DOI: 10.1134/S1070427216060112

[A.O. Krasnova, N.V. Glebova, A.A. Nechitailov. Russ. J. Appl. Chem., 89 (6), 916 (2016). DOI: $10.1134 / \mathrm{S} 1070427216060112]$

[13] M. Uchida, Y. Aoyama, M. Tanabe, N. Yanagihara, N. Eda, A. Ohta. J. Electrochem. Soc., 142, 2572 (1995). DOI: $10.1149 / 1.2050055$

[14] J. McBreen, H. Olender, S. Srinivasan, K. Kordesch. J. Appl. Electrochem., 11, 787 (1981). DOI: 10.1007/BF00615184

[15] D. Pantea, H. Darmstadt, S. Kaliaguine, L. Summchen, C. Roy. Carbon, 39, 1147 (2001).

DOI: $10.1016 / \mathrm{S} 0008-6223(00) 00239-6$
[16] E. Antolini. Appl. Catal. B Environ., 88, 1 (2009). DOI: $10.1016 /$ j.apcatb.2008.09.030

[17] Электронный ресурс. Режим доступа: URL. http://www.nanotc.ru/producrions/87-cnm-taunit

[18] S. Litster, G. McLean. J. Power Sources, 130, 61 (2004). DOI:10.1016/j.jpowsour.2003.12.055

[19] K.R. Cooper, M. Smith. J. Power Sources, 160, 1088 (2006). DOI: 10.1016/j.jpowsour.2006.02.086

[20] А.А. Нечитайлов, Н.В. Глебова. Электрохимия, 50, 835 (2014). DOI: 10.1134/S1023193514080102 [A.A. Nechitailov, N.V. Glebova. Russ. J. Electrochemi., 50 (8), 751 (2014). DOI: $10.1134 / \mathrm{S} 1023193514080102]$

[21] F. Beck, M. Dolata, E. Grivei, N. Probst. J. Appl. Electrochem., 31, 845 (2001). DOI: 10.1023/A:1017529920916 